\title{
Network Analysis in the Social Sciences
}

\author{
Stephen P. Borgatti, Ajay Mehra, Daniel J. Brass \& Giuseppe Labianca*
}

\begin{abstract}
Over the last decade, there has been an explosion of interest in network research across the physical and social sciences. For social scientists, the theory of networks has been a goldmine, yielding explanations for social phenomena in a wide variety of disciplines from psychology to economics. In this essay, we review the kinds of things that social scientists have tried to explain using social network analysis and provide a nutshell description of the basic assumptions, goals and explanatory mechanisms prevalent in the field. We also give a brief history of network research in the social sciences and identify some historical criticisms and current challenges facing the field. We hope to contribute to a dialogue among researchers from across the physical and social sciences who share a common interest in understanding the antecedents and consequences of network phenomena.
\end{abstract}

One Sentence Summary: Social network theory explains a wide variety of phenomena in the social sciences.

Submission Category: REVIEW

"This manuscript has been accepted for publication in Science. This version has not undergone final editing. Please refer to the complete version of record at http://www.sciencemag.org/. The manuscript may not be reproduced or used in any manner that does not fall within the fair use provisions of the Copyright Act without the prior, written permission of AAAS." 
* The authors are researchers at the LINKS Center for Network Research in Business, Gatton College of Business and Economics, University of Kentucky, Lexington, KY 40506-0034. Email: sborgatti@uky.edu, ajay.mehra@uky.edu, dbrass@uky.edu, and joe.labianca@uky.edu.

One of the most potent ideas in the social sciences is the notion that individuals are embedded in thick webs of social relations and interactions. Social network theory provides an answer to a question that has preoccupied social philosophy since the time of Plato, namely, the problem of social order: how autonomous individuals can combine to create enduring, functioning societies. Network theory also provides explanations for a myriad of social phenomena, from individual creativity to corporate profitability. Readers of Science are already familiar with network research in physics and biology (1), but may be less familiar with what has been done in the social sciences. In this essay, we provide a brief history of network research in the social sciences together with an overview of the basic assumptions, goals, and explanatory mechanisms of social network theory.

\section{History ${ }^{1}$}

In the fall of 1932, there was an epidemic of runaways at the Hudson School for Girls in upstate New York. In a period of just two weeks, 14 girls had run away - a rate 30 times higher than the norm. Jacob Moreno, a psychiatrist, suggested the reason for the spate of runaways had less to do with individual factors pertaining to the girls' personalities and motivations than with the positions of the runaways in an underlying social network (3). Moreno and his collaborator, Helen Jennings, had mapped the social network at Hudson using "sociometry," a technique for eliciting and graphically representing individuals' subjective feelings towards one another (Fig. 1). The links in this social network, Moreno argued, provided channels for the flow of social influence and ideas among the girls. In a way that even the girls themselves may not have been conscious of, it was their location in the social network that determined whether and when they ran away.

\footnotetext{
${ }^{1}$ For a thorough history of the field, see the definitive work by Freeman (2).
} 


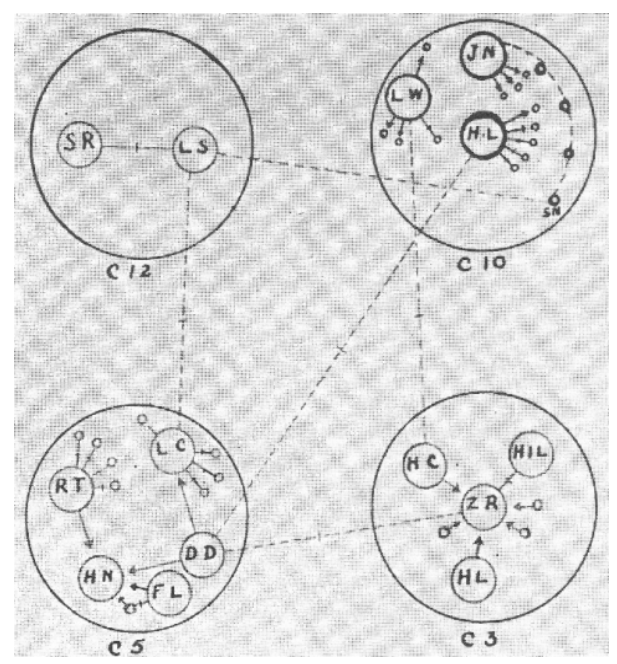

Figure 1. Moreno's network of runaways. The four largest circles $(\mathrm{C12}, \mathrm{C10}, \mathrm{C5}, \mathrm{C} 3)$ represent cottages in which the girls lived. Each of the circles within the cottages represents an individual girl. The 14 runaways are identified by initials (e.g.) SR). All non-directed lines between a pair of individuals represent feelings of mutual attraction. Directed lines represent one-way feelings of attraction.

Impressed by the rapid advances being made during his time in the physical and biological sciences, Moreno envisioned sociometry as a kind of physics, complete with its own "social atoms" and its laws of "social gravitation" (3). The idea of modeling the social sciences after the physical ones was not, of course, Moreno's invention. A hundred years before Moreno, the social philosopher Comte hoped to found a new field of "social physics." Fifty years after Comte, the French sociologist Durkheim had argued that human societies were like biological systems in that they were made up of interrelated components. As such, the reasons for social regularities were to be found not in the intentions of individuals but in the structure of the social environments in which they were embedded (4). Moreno's sociometry provided a way of making this abstract social structure tangible.

In the 1940 s and 50s, work in social networks advanced along several fronts. One front was the use of matrix algebra and graph theory to formalize fundamental social-psychological concepts such as groups and social circles in network terms, making it possible to objectively discover emergent groups in network data (5). Another front was the development of a program of laboratory experimentation on networks. Under the leadership of Alex Bavelas, a team of researchers at the Group Networks Laboratory at MIT began studying the effects of different communication network structures on the ability of groups to solve problems (6). By varying the pattern of who 
could communicate with whom, the researchers were able to examine the effects of a group's network structure on the speed and accuracy of the group's problem solving. Figure 2 shows four of the structures that were tested. It was found that the more centralized structures, such as the star structure, outperformed decentralized structures, such as the circle, even though it could be shown mathematically that the circle structure had, in principle, the shortest minimum solution time (7). Why the discrepancy? Achieving the mathematically optimal solution would have required the nodes to execute a fairly complex sequence of information trades in which no single node served as integrator of the information. But the tendency in human networks seemed to be for the more peripheral members of a network (i.e., the nodes colored blue in the "Star," "Y," and "Chain" networks in Fig. 2) to channel information to the most central node (i.e., the nodes colored red in Fig. 2) who then decided what the correct answer was and sent this answer back out to the other nodes. The fastest performing network structures were those in which the distance of all nodes from the obvious integrator was the shortest. ${ }^{2}$

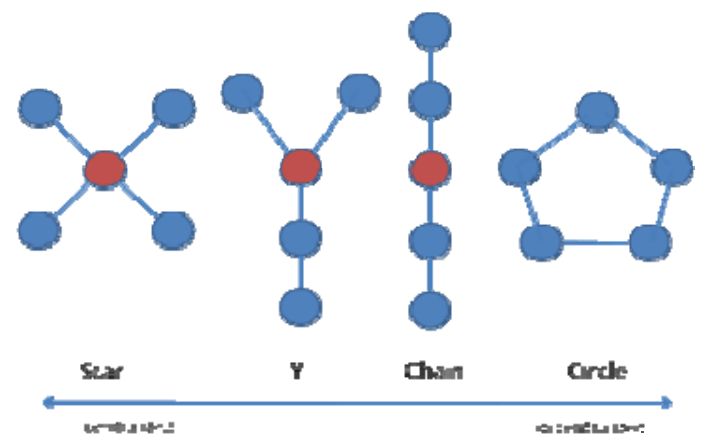

Figure 2. Four network structures examined by Bavelas and colleagues at MIT. Each node represents a person; each line represents a potential channel for interpersonal communication. The most central node in each network is colored red.

The work done by Bavelas and his colleagues at MIT captured the imagination of researchers in a number of fields, including psychology, political science, and economics. In the 1950s, Kochen, a mathematician, and de Sola Pool, a political scientist, wrote a highly circulated paper, eventually published in $1978,(9)$ which tackled what is known today as the "small world" problem. They asked the question: If two persons are selected at random from a population, what were the chances that they would know each other, and, more generally, how long a chain of

\footnotetext{
${ }^{2}$ Later experiments suggested that this result was contingent on other factors. For example, several experiments showed that, as the complexity of puzzles increased, decentralized networks performed better (8)
} 
acquaintanceship would be required to link them? On the basis of mathematical models, they speculated that in a population like the United States, at least $50 \%$ of pairs could be linked by chains with no more than two intermediaries. Twenty years later, Stanley Milgram tested their propositions empirically, leading to the now popular notion of "six degrees of separation" (10).

During this period, network analysis was also used by sociologists interested in studying the changing social fabric of cities. The common conviction at the time was that urbanization destroyed community, and that cities played a central role in this drama. These sociologists saw concrete relations between people-love, hate, support, and so on - as the basic stuff of community, and they used network analysis to represent community structure. For example, researchers interviewed 1,050 adults living in fifty northern Californian communities with varying degrees of urbanism about their social relations (11). The basic procedure for eliciting network data was to get respondents (egos) to identify people (alters) with whom they had various kinds of relationships and then to also ask ego about the relationships between some or all of the alters. The study examined the size, composition, and density or interconnectedness of the resultant personal or "ego-networks." It found that urbanism did in fact reduce network density, which, in turn, was negatively related to psychological measures of satisfaction and overall wellbeing. A similar study of 369 boys and 366 girls between the ages of 13 and 19 in a Midwestern town of about 10,000 residents found that the adolescents' behaviors were strongly influenced by the "cliques" to which they belonged (12). The representation and analysis of community network structure remains at the forefront of network research in the social sciences today, with growing interest in unraveling the structure of computersupported virtual communities that have proliferated in recent years (13).

By the 1960s, the network perspective was thriving in anthropology. Influenced by the pioneering work of Radcliffe Brown (14), there were three main lines of inquiry. First, at the conceptual level, anthropologists like S. F. Nadel began to see societies not as monolithic entities but rather as a "pattern or network (or 'system') of relationships obtaining between actors in their capacity of playing roles relative to one another" (15). Second, building on the insights of the anthropologist Levi-Strauss, scholars began to represent kinship systems as relational algebras which consisted of a small set of generating relations (such as 'parent of' and 'married to') together with binary composition operations to construct derived relations such as "in-law" (a parent of the 
person I am married to) and "cousin" (a child of a child of my parent's parent who isn't a child of my parent). It was soon discovered that the kinship systems of such peoples as the Arunda of Australia formed elegant mathematical structures that gave hope to the idea that deep law-like regularities might underlie the apparent chaos of human social systems $(16,17)$.

Third, a number of social anthropologists began to use network-based explanations to account for a range of outcomes. For example, a classic ethnographic study by Bott (18) examined 20 urban British families and attempted to explain the considerable variation in the way husbands and wives performed their conjugal roles. In some families, there was a strict division of labor: husband and wife carried out distinct household tasks separately and independently. In other families, the husband and wife shared many of the same tasks and interacted as equals. Bott found that the degree of segregation in the role-relationship of husband and wife varies directly with the connectedness (or density) of the family's social network. The more connected the network, the more likely the couple would maintain a traditional segregation of husband and wife roles. Bott's work provided some of the earliest evidence suggesting that the structure of the larger network in which a dyad is embedded can affect relations and behaviors within the dyad.

In the 1970s, the center of gravity of network research shifted to sociology. Working in the tradition of anthropological kinship algebras, Lorrain and White (19) sought ways of building reduced models of the complex algebras created when all possible compositions of a set of relations were constructed (e.g., the spouse of the parent of the parent of ...). By collapsing together nodes that were structurally equivalent - i.e., those that had similar incoming and outgoing ties - they could form a new network (a reduced model) in which the nodes consisted of structural positions rather than individuals. This idea mapped well with the anthropologists' view of social structure as a network of roles rather than individuals, and was broadly applicable to the analysis of roles in other settings, such as the structure of the U.S. economy (20). It was also noted that structurally equivalent individuals faced similar social environments and therefore could be expected to develop similar responses, such as similar attitudes or behaviors (21).

Another key contribution of this period was the influential Strength of Weak Ties theory (SWT) developed by Mark Granovetter (22). Granovetter argued that strong ties tend to be "clumpy" in the sense that that one's close 
contacts tend to know each other. As a result, some of the information they pass along is redundant - what a person hears from contact $A$ is the same as what the person heard from $B$. In contrast, weak ties (e.g., mere acquaintances) can easily be unconnected to the rest of one's network, and therefore more likely to be sources of novel information. Twenty years later, this work has developed into a general theory of social capital - the idea that whom a person is connected to, and how these contacts are connected to each other, enable people to access resources that ultimately lead them to such things as better jobs and faster promotions (23).

By the 1980's, social network analysis had become an established field within the social sciences, with a professional organization (INSNA), an annual conference (SUNBELT), specialized software (e.g., UCINET) and its own journal (Social Networks). In the 1990s, network analysis radiated into a great number of fields, including physics and biology. It also made its way into several applied fields such as management consulting (24), public health (25), and crime/war fighting (26). In management consulting, network analysis is often applied in the context of knowledge management, where the objective is to help organizations better exploit the knowledge and capabilities distributed across its members. In public health, network approaches have been important both in stopping the spread of infectious diseases and in providing better health care and social support.

Of all the applied fields, national security is probably the area that has most embraced social network analysis. Crime-fighters, particularly those fighting organized crime, have used a network perspective for many years, covering walls with huge maps showing links between "persons of interest." This network approach is often credited with contributing to the capture of Saddam Hussein. In addition, terrorist groups are widely seen as networks rather than organizations, sparking research on how to disrupt functioning networks (27). At the same time, it is often asserted that it takes a network to fight a network, sparking military experiments with decentralized units.

\section{Social Network Theory}

\section{Types of Ties}

In the physical sciences, it is not unusual to regard any dyadic phenomena as a network. In this usage, a network and a mathematical graph are synonymous, and a common set of techniques is used to analyze all 
instances, from protein interactions to co-authorship to international trade. In contrast, social scientists typically distinguish among different kinds of dyadic links both analytically and theoretically. For example, the typology shown in Figure 3 divides dyadic relations into four basic types - similarities, social relations, interactions, and flows - which are discussed below. Much of social network research can be seen as working out how these different kinds of ties affect each other.

\begin{tabular}{|c|c|c|c|c|c|c|c|c|}
\hline \multicolumn{3}{|c|}{ Similarities } & \multicolumn{4}{|c|}{ Social Relations } & \multirow[t]{2}{*}{ Interactions } & \multirow[t]{2}{*}{ Flows } \\
\hline Location & Membership & Attribute & Kinship & Other Role & Affective & Cognitive & & \\
\hline $\begin{array}{l}\text { e.g., } \\
\text { Same } \\
\text { spatial \& } \\
\text { temporal } \\
\text { space }\end{array}$ & $\begin{array}{l}\text { e.g., } \\
\text { Same clubs, } \\
\text { Same events } \\
\text { etc. }\end{array}$ & $\begin{array}{l}\text { e.g., } \\
\text { Same } \\
\text { gender, } \\
\text { Same } \\
\text { attitude } \\
\text { etc. }\end{array}$ & $\begin{array}{l}\text { e.g., } \\
\text { Mother of, } \\
\text { Sibling of }\end{array}$ & $\begin{array}{l}\text { e.g., } \\
\text { Friend of, } \\
\text { Boss of, } \\
\text { Student of, } \\
\text { Competitor }\end{array}$ & $\begin{array}{l}\text { e.g., } \\
\text { Likes, } \\
\text { Hates, } \\
\text { etc. }\end{array}$ & $\begin{array}{l}\text { e.g., } \\
\text { Knows, } \\
\text { knows } \\
\text { about, sees } \\
\text { as happy, } \\
\text { etc. }\end{array}$ & $\begin{array}{l}\text { e.g., } \\
\text { Sex with, } \\
\text { Talked to, } \\
\text { Advice to, } \\
\text { Helped, } \\
\text { Harmed, } \\
\text { etc. }\end{array}$ & $\begin{array}{l}\text { e.g., } \\
\text { Information, } \\
\text { beliefs, } \\
\text { personnel, } \\
\text { resources, } \\
\text { etc. }\end{array}$ \\
\hline
\end{tabular}

Figure 3. A typology of ties studied in social network analysis.

Similarities include spatial and temporal proximity as well as co-membership in groups and events and sharing socially significant attributes, such as race or class. Similarities are not seen as social ties in themselves but rather as conditions or states that increase the probability of forming other kinds of ties, and therefore shape social networks. For example, physical proximity creates opportunities for interaction, which in turn can forge social relations. Social relations are the canonical types of ties that most sociological theorizing about social networks is based on. Like similarities, social relations are conceptualized as continuous properties. In contrast, interactions are typically conceptualized as discrete events that can be counted over a period of time. We typically view interactions as being facilitated by and occurring in the context of social relations (and vice-versa). For example, friends (social relation) give each other advice (interaction). At the same time, through interactions, social relations may evolve (e.g., friends can become business partners). Flows are those tangible and intangible things that are transmitted through interactions. Ideas are transmitted through communication; viruses and material resources through physical contact, and so on. Flows are not typically measured but rather inferred from interactional and relational data. An important element of network theorizing - though perhaps rarely explicit - has been to construct indices of expected flows given underlying social relations (28). 
Social scientists typically view each kind of tie as a separate network, each with a potentially unique structure and different implications for the nodes involved. For example, the advice network in a corporate office may have a radically different structure than the friendship network for the same nodes. Rather than searching for a single, "best" relation to serve as an indicator of the social network, researchers typically measure multiple relations and examine how they relate to each other. For instance, a major relational perspective in economic sociology is embeddedness, the idea that economic transactions among actors are influenced by the social relations among the same set of actors (29). The behavior of firms, for example, can depart from market expectations because of the social ties in which economic relations between firms are embedded (30). Similarly, social scientists have been interested in the extent to which one type of tie (e.g., friendship) may be appropriated for a different use (e.g., obtain a loan) (31).

\section{Key Theoretical Concepts}

As in the study of isomers in chemistry, a fundamental axiom of social network analysis is the concept that structure matters. For example, teams with the same composition of member skills can perform very differently depending on the patterns of relationships among the members. Similarly, at the level of the individual node, a node's outcomes and future characteristics depend in part on its position in the network structure. Whereas traditional social research explained an individual's outcomes or characteristics as a function of other characteristics of the same individual (e.g., income as a function of education and gender), social network researchers look to the individual's social environment for explanations, whether through influence processes (e.g., individuals adopting their friends' occupational choices) or leveraging processes (e.g., an individual can get certain things done because of the connections she has to powerful others).

A key task of social network analysis has been to invent graph-theoretic properties that characterize (a) network structures (at the network level of analysis), (b) network positions (at the node level of analysis), and (c) dyadic properties (at the dyad level). At the network level of analysis, two properties are well-known: cohesion and shape. Cohesion refers to the connectedness of the structure and includes properties such as density, characteristic path length, and fragmentation. Cohesion measures are also used to define and detect subgroups network regions that have specific cohesive properties, such as high density, short distances or multiple 
independent paths among members (32). Shape refers to the overall distribution of ties and includes properties such as core-peripheriness, clumpiness and scale-freeness of the degree distribution.

At the node level of analysis, the most widely studied concept is centrality - a family of node-level properties relating to the structural importance or prominence of a node in the network. For example, one type of centrality is Freeman's betweenness, which captures the property of frequently lying along the shortest paths between pairs of nodes (33). This is often interpreted in terms of the potential power that an actor might wield due to the ability to slow down flows or to distort what is passed along in such a way as to serve the actor's interests. For example, Padgett and Ansell (34) analyzed historical data on marriages and financial transactions of the powerful Medici family in $15^{\text {th }}$ century Florence. The study suggested that the Medici's rise to power was a function of their position of high betweenness within the network, which allowed them to broker business deals and serve as a crucial hub for communication and political decision making.

Finally, at the dyadic level, the two fundamental families of properties are dyadic cohesion and equivalence. Dyadic cohesion refers to a set of concepts relating to the social closeness of a pair of nodes, such as geodesic distance (the length of the shortest path from one to the other), or multiplexity (the number of different kinds of relations that bind a pair of nodes). Equivalence refers to the extent to which pairs of nodes play similar structural roles in the network, such as whether they are isomorphic. For example, in Figure 4, nodes $b, d, g$ and $i$ are structurally similar. Indeed, if the colors and labels of all the nodes were lost and the graph were picked up, twirled around and set back down, it would be impossible to tell which of these was which, since they are structurally identical. But all four ( $b, d, g$, and $i)$ could be distinguished from $e$ and $f$ (whose friends are unconnected), and from $a, c, h$ and $j$ (who each belong to exactly 2 cliques of size 3 ).

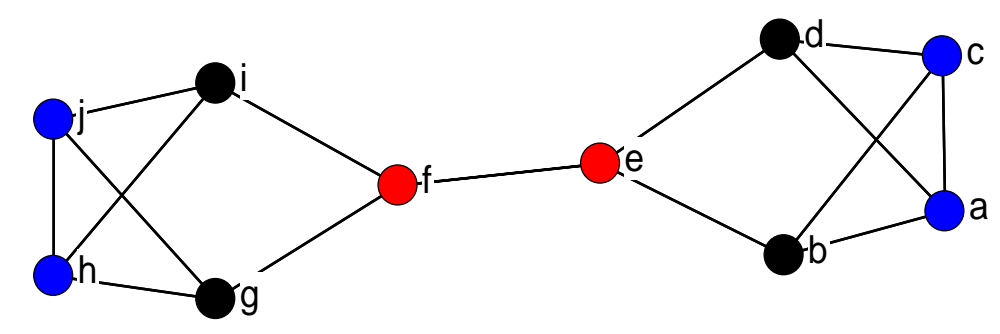


Figure 4. Similarly colored nodes are structurally isomorphic.

\section{Research Questions}

In the physical sciences, a key research goal has been formulating universal characteristics of non-random networks, such as the property of having a scale-free degree distribution. In the social sciences, however, researchers have tended to emphasize variation in structure across different groups or contexts, using these variations to explain differences in outcomes. For example, Granovetter famously argued that when the city of Boston sought to absorb two neighboring towns, the reason that one of the towns was able to successfully resist was that its more diffuse network structure was more conducive to collective action (22).

A research goal that the social and physical sciences have shared has been to explain the formation of network ties and, more generally, to predict a host of network properties, such as the clusteredness of networks or the distributions of node centrality. In the social sciences, most of the work of this type has been conducted at the dyadic level to predict which nodes will have which kinds of ties to which other nodes. For example, what is the basis of friendship ties? How do firms pick alliance partners? A host of explanations have been proposed in different settings, but we find they can usefully be grouped into two basic categories: opportunity-based antecedents and benefit-based antecedents.

The opportunity-based explanations focus on the likelihood that two nodes will come into contact; they include such factors as geographic proximity (e.g., most interaction occurs among those who are physically close to each other (35), social proximity (e.g., having a friend in common increases likelihood of meeting), and relative group sizes (e.g., members of the numeric minority in a group tend to have more friends with members of the majority group than vice versa) (36). The benefit-based explanations typically posit some kind of utility/discomfort maximization/minimization that leads to tie formation. For example, one explanation for homophily (the tendency to be socially attracted to those similar to oneself along socially significant dimensions) is that communication is easier and more effective among those that have similar backgrounds (37). Similarly, being enemies with the friend of a friend can create a tension that can be reduced by either dropping the friend or reconciling with the enemy. Another example is the tendency to form ties with nodes that have resources that one lacks (20). 
While there are many studies of network antecedents, the primary focus of network research in the social sciences has been on the consequences of networks. Perhaps the most fundamental axiom in social network research is that a node's position in a network determines in part the opportunities and constraints that it encounters, and in this way plays an important role in a node's outcomes. This is the network thinking behind the popular concept of social capital, which in one formulation posits that the rate of return on an actor's investment in their human capital (i.e., their knowledge, skills and abilities) is determined by their social capital (i.e., their network location) (38).

A multitude of node outcomes have been studied as consequences of social network variables. Broadly speaking, these outcomes fall into two main categories, which we refer to as homogeneity and performance. Node homogeneity refers to the similarity of actors with respect to behaviors or internal structures. For example, if the actors are firms, one well-known area of research tries to predict which firms adopt the same organizational governance structures (39); similarly, where the nodes are individuals, a key research area has been the prediction of similarity in time-to-adoption of an innovation for pairs of actors (40). Performance refers to a node's outcomes with respect to some good. For example, researchers have found that actors with more structural holes in their ego-networks at work have better ideas (41). Similarly, at the firm level, researchers have found that firm centrality predicts the firm's ability to innovate, as measured by number of patents secured (42), as well as to perform well financially (43). Other research has linked individual centrality with power and influence (44).

\section{Theoretical Mechanisms}

Causal explanation in social network research invokes mechanisms, which are the underlying processes that account for observed relationships among variables. Here we identify four canonical mechanisms that are employed in social network research.

Transmission. Perhaps the most common mechanism in social network analysis is some form of direct transmission from node to node. Whether this is a physical transfer, as in the case of material resources such as money, or a mimetic/imitative process, such as the contagion of ideas, the underlying idea is that something flows along a network path from one node to the other. Thus, a pair of nodes may exhibit similar attitudes or behavior because 
one node has influenced the other, either directly or through a path of intermediaries. ${ }^{3}$ For example, a person who is unsure about how to behave in a given setting may actively choose to imitate social leaders. Alternatively, a node may coerce another into performing some behavior. In a classic illustration of the transmission mechanism, the speed and adaptation of "poison pills," a corporate governance practice that came to be widely adopted in the 1980s as a defense against hostile takeovers, was shown to diffuse like an infection from corporate board to board through shared directors. The links in the network provided the conduits for the flow of information and norms between corporations (45). The transmission mechanism is also invoked in explanations of differential performance. For example, researchers have found that the ability to access resources through one's social ties is a critical factor in achieving social status (46).

Adaptation. The adaptation mechanism states that nodes become homogeneous as a result of experiencing and adapting to similar social environments. Much like explanations of convergent forms in biology, if two nodes have ties to the same (or equivalent) others they face the same environmental forces and are likely to adapt by become increasingly similar. For example, two highly central nodes in an advice network could develop similar distaste for the telephone and email, because both receive so many requests for help through these media. Unlike the case of transmission, the state of "distaste for communication media" is not transmitted from one node to another, but rather is similarly created in each node because of their similar relations to others. This mechanism can be used to explain how relational roles affect outcomes (e.g., two professors have similar attitudes about students although neither is connected nor transmits anything to the other).

Binding. The binding mechanism is similar to the old concept of covalent bonding in chemistry. The idea is that social ties can bind nodes together in such a way as to construct a new entity whose properties can be different from those of its constituent elements. Binding is one of the mechanisms behind the popular notion of the performance benefits of "structural holes" (Fig. 5). Given an ego-network (the set of nodes with direct ties to a focal node, called ego, together with the set of ties among members of the ego network), a structural hole is the absence of a tie among a pair of nodes in the ego-network (23). A well-established proposition in social network

\footnotetext{
${ }^{3}$ By extension, the transmission mechanism suggests that cohesive subgroups (network regions that are highly cohesive) will be more homogeneous than randomly selected sets of nodes of equal size.
} 
analysis is that egos with lots of structural holes are better performers in certain competitive settings (38). The lack of structural holes around a node means that the node's contacts are "bound" together - they can communicate and coordinate so as to act as one, creating a formidable 'other' to negotiate with. This is the basic principle behind the benefits of worker's unions and political alliances. In contrast, a node with many structural holes can play unconnected nodes against each other, dividing and conquering. It is also the basic principle behind the notion of an agent - someone who is "bound" to or acts in the interests of another.

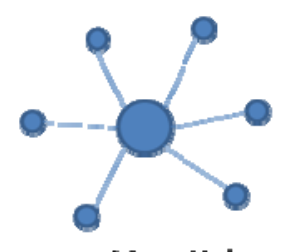

Many Holes

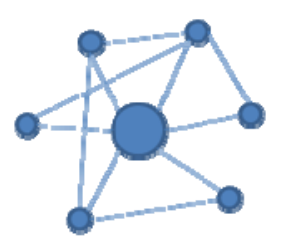

Few llokes

Figure 5. Two illustrative ego networks. The one on the left contains many structural holes; the one on the right contains few.

Exclusion. The exclusion mechanism refers to competitive situations in which one node, by forming a relation with another, excludes a third node. To illustrate, consider a "chain" network (see Figure 6) in which nodes are allowed to make pairwise "deals" with those they are directly connected to. Node $d$ can make a deal with either node $c$ or node $e$, but not both nodes. Thus, $d$ can exclude $c$ by making a deal with $e$. A set of experiments (47) showed that nodes $b$ and $d$ have high bargaining power, while $a, c$ and $e$ have low power. Of special interest is the situation of $c$, which is more central than, and has as many trading partners, as $b$ and $d$. However, $b$ and $d$ are stronger because each have partners ( $a$ and $e$ ) that are in weak positions (no alternative bargaining partners). Having only strong nodes to bargain with makes $c$ weak. In this way, a node's power becomes a function of the powers of all other nodes in the network, and results in a situation in which a node's power can be affected by changes in the network far away from the node. For example, adding additional nodes as possible trading partners to $a$ and $e$ strengthens $c^{\prime}$ s position immensely. Indeed, the power of a node can be estimated by the net surplus of odd and even-length paths from the node to all others (48). For example, the high-power nodes $b$ and $d$ are in positions such that they have three paths of odd-length and only one path of even length. In contrast, the low 
nodes $a, c$, and $e$ have two paths of odd length and two paths of even length. ${ }^{4}$ An example of the exclusion mechanism occurs in business-to-business supply chains. When a firm intentionally locks up a supplier to an exclusive contract, competitor firms are excluded from accessing that supplier, leaving them vulnerable in the marketplace. Thus, when Nike signs an exclusive apparel contract with Major League Baseball, other apparel firms, such as Reebok, suffer directly in terms of not being able to sell jerseys, but also suffer by being in weaker negotiating positions with their own customer firms, such as Dick's Sporting Goods.

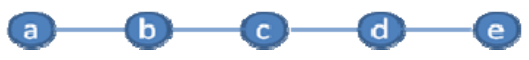

Figure 6. A five person exchange network. Nodes represent persons; lines represent exchange relations.

\section{Fundamental Metaphors}

Underlying the specific explanatory mechanisms that have been proposed in social network analysis are at least two fundamental metaphors, which we refer to here as the Flow Model and the Architecture Model. These metaphors are important because they guide the development of new concepts and methods in the field.

Flow Model. The flow model essentially views a network as a system of pipes (or roads) through which things flow. A surprising amount of extant theorizing about the consequences of network properties is based on this simple premise. For example, if what is flowing through the network is information, all else being equal, nodes with a high number of direct ties should have a greater probability of exposure to any bit of information flowing through the network than nodes with only a few ties. At the network level of analysis, the existence of nodes with many direct ties makes the network highly searchable.

Indirect ties and path lengths are also inherent in the flow metaphor. For example, two nodes, A and B, could have the same number of ties, but A could have a much higher probability of receiving the information if the nodes it has ties with have many more ties than the nodes that B has ties with. Nodes that are connected to most others by fairly long paths can be expected to receive whatever is flowing through the network later, on average, than those who have fewer path lengths to travel to all other nodes. In addition, nodes that lie along a greater share of

\footnotetext{
${ }^{4}$ Experimental exchange networks have also been fruitfully explored from a game-theoretic perspective (49)
} 
shortest paths between pairs of others (i.e., those high in betweenness) can be seen as structurally more important since their removal or their refusal to pass along flows would tend to have a larger effect on the network than the same behavior in more peripheral nodes. For example, individuals central in each of these three flow measures (direct ties, path lengths, and betweenness centrality) are the most powerful in organizations (44). Architecture model. Another fundamental metaphor that motivates social network theorizing is the view of ties as something akin to girders or bones that create a structure upon which socio-cultural systems are draped. The architecture model is responsible for some of the most beautiful concepts in social network analysis, such as the lattice of regular equivalences. The notion of regular equivalence was invented to formalize the notion of a social role. The idea is that a social system - modeled as a network - consists of a set of (unknown) positions or roles that have certain characteristic relationships with other roles. The question is whether, given an observed network, it is possible to infer the roles.

The notion of regular equivalences can be described by the equation $C(u)=C(v) \rightarrow C(N(u))=C(N(v))$, where $N(u)$ refers to the set of nodes that $u$ is adjacent to, and $C(N(u))$ is the set of distinct colors or roles represented by u's contacts. The equation says - recursively - that if two nodes are playing the same role, then they will have ties to equivalent others, though not necessarily the same others and not necessarily in the same quantities. Thus, a doctor has certain relationships with a given set of nurses and patients, and another doctor has similar relationships with a (possibly) different but equivalent set of nurses and patients. An illustration is provided in Figure 7, which partitions the nodes into three equivalence classes. In the diagram, it can be seen that the condition specified by the equation holds for every pair of nodes in the same equivalence class. For example, nodes N1 and N3 are both nurses; both socialize with other nurses and both assist doctors. 


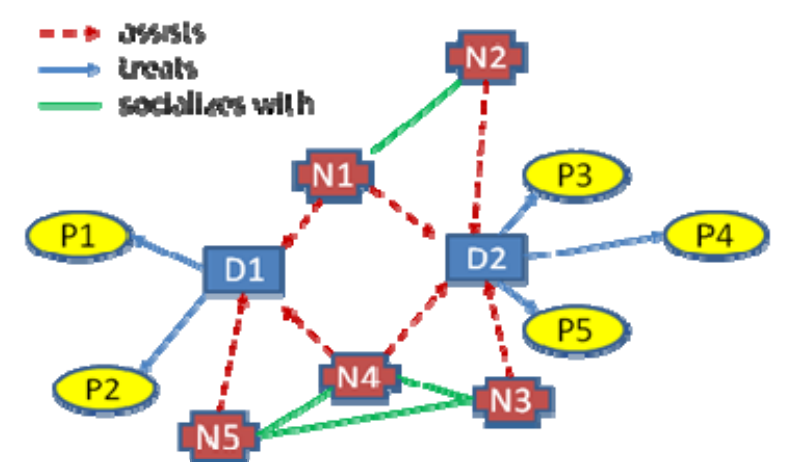

Figure 7. Illustrative relations among a set of doctors, nurses and patients.

The definition of regular equivalence allows us to build a reduced model of the network that preserves the essential structure. Figure 8 shows the model (known as a blockmodel) associated with the regular equivalence depicted in Figure 7. The model states that doctors receive assistance ties from nurses and give treatment ties to patients.

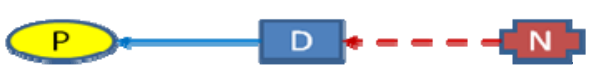

Figure 8. Regular equivalence blockmodel.

\section{Criticisms and Challenges}

Network research is "hot" today, with the number of articles in the Web of Science on the topic of "social networks" nearly tripling in the past decade. The number of articles employing measures originally developed by social network researchers has also increased radically in other scientific fields, including biology and physics (50). However, network research is not without criticism. Within the social sciences, social network research has been subject to a number of persistent criticisms over the years. We examine several of these criticisms here.

Theory. Perhaps the oldest criticism is that the field lacks a (native) theoretical understanding - it is "merely descriptive" or "just methodology." It is indeed one of the strengths of the field that it provides excellent methods and concepts that can be used to characterize networks and the positions of nodes within them. It is also true that newcomers to the field tend to be dazzled by these abilities and tend to focus on simply describing networks - e.g., 
characterizing them as small worlds or as scale free. But the notion that there is no native network theory seems patently wrong, at least in the social sciences today. In fact there is so much of it that one of the main purposes of this article is to organize and simplify this burgeoning body of theory. The criticism has probably lingered for a number of reasons, including (i) the novelty, mathematical sophistication, and richness of the social network analysis methodological toolkit, (ii) the apparent applicability and portability of network concepts to a wide variety of phenomena, just as statistics can be applied to all kinds of problems, and (iii) a tendency among some social scientists to associate all things mathematical with tools or methods.

Agency. Another lingering criticism in social science circles is that network research lacks agency in the sense that it neglects subjectivity and human intentionality (51). This criticism suggests that the nodes tend to be conceptualized as passive and interchangeable receptacles, wholly determined by their positions or environments rather than active agents who manage their own destinies as well as shape the network around them. To some extent this is true: for some network researchers, the appeal of the field is precisely the possibility of explaining human action without recourse to what they would regard as mystical factors, such as intentions and dispositions. They would argue that explanations in social science too often come down to "people do things because they want to." On the other hand, this orientation varies by discipline. In the management sciences, network research is very likely to conceive of nodes as strategic players maximizing self-interest. For example, management researchers have shown that individuals with different psychological characteristics actively construct different kinds of social, networks in the workplace (52). Also, much of the work on antecedents of networks is based on a model of an active agent making choices of who to have ties with. This is also true of much of the work on social capital - the notion that one can invest in one's ties or position and obtain a return on that investment (38).

Dynamics. This criticism refers to the lack of attention that social network researchers are thought to have paid to the evolution of networks - how ties form, are maintained, and decay over time. This criticism is probably overstated - as pointed out earlier, a great deal is known about the principles behind who forms ties with whom. However, it is also true that the bulk of the work in social network analysis has focused on the consequences of networks rather than the antecedents. This is natural in the case of a new field, which must gain legitimacy by showing that it provides new explanations for existing problems. Once the value of network variables is accepted, 
it becomes understandable why one would be interested in exploring the antecedents of those variables. An important challenge, however, is the problem of endogeneity, which is essentially that, in social phenomena, effects can also be causes. For example, while researchers have shown that central nodes in workplace networks are more successful, it is equally clear that success attracts more partners, increasing centrality. Similarly, it is known that actors tend to interact with other actors who have similar behaviors. This occurs both because actors select others on the basis of similar behaviors (e.g., smokers in an organization tend to meet in designated smoking areas), and because tied actors tend to influence each other (e.g., a teenager may start smoking as a result of their association with another teen that is a smoker). Recent advances in the analysis of longitudinal network data (53) and the increased use of agent-based simulation modeling will allow researchers to estimate the relative effects of selection and influence.

Cognition. A key element of social networks is that the nodes are capable of cognition. People are reflective and projective creatures, and this affects how they react to their network positions, and how they change their network positions in pursuit of their goals. As a result, network researchers in the social sciences have become increasingly interested in how individual actors perceive (and systematically misperceive) the structure of the networks they are embedded in, and the consequences these perceptions can have for such outcomes as workplace performance (54). Similarly, organizational theorists have examined how the market's perception of ties between one firm (A) and another firm (B) can change the economic resources that are available to $A(55)$. How the nodes in a social network perceive and misperceive their own and others' network ties, and with what consequences, is a fertile topic for future research. It is also a topic with implications for such foundational methodological questions as when self-report is a valid source of data on network ties.

The Double-Hermeneutic. A foreseeable challenge for network research in the social sciences is that social science concepts can become a part of the very world they describe. Social science theories can diffuse through a population, influencing the way people see themselves and how they act, a phenomenon that sociologist Anthony Giddens described as the double-hermeneutic (56). A case in point is the increasing use of network analysis as a management tool. Suppose, for example, that an organization monitors employee emails and analyzes them using social network analysis. Individuals who are well-connected are praised for their collaborativeness and 
involvement. As a result, people begin to communicate more widely, even if meaninglessly, in order to come out well in the "test".

Another case is provided by the explosion in the popularity of social networking sites, such as Facebook and Linkedin, which make one's connections highly visible and salient. Many of these sites offer users detailed information about the structure and content of their social networks, as well as suggestions for how to enhance their social networks. The question arises as to whether this enhanced awareness of social network theories may alter the way in which people create, maintain, and leverage their social networks. If it does not, the prescriptive value of social network theory is unclear. If it does, social network theorists may need to continually adjust their theories and the prescriptions they draw from them.

\section{Closing Observations}

Our objective in this piece has been to provide a theoretically oriented overview of network research in the social sciences. ${ }^{5}$ Of course, focusing on the social sciences alone begs a comparison with network research in other fields, such as physics, computer science and biology. Such comparisons are notoriously risky because they involve making sweeping generalizations. Nonetheless, we offer a few observations.

A notable difference between network research in the physical sciences and network research in the social sciences is the interest demonstrated by the former in simply describing the structure of real networks and determining the extent to which these descriptions are universal. For example, early work by physicists on both small world and scale-free networks sought to establish these properties as characteristic of all real networks. In contrast, in the social sciences, descriptive studies have generally been underappreciated and the probability of near-universal descriptions highly discounted. Social science work on social networks has instead been predicated on expecting variation in network structures, and using this variation as explanatory of what happens to different networks. In addition, when network research in the physical sciences have been more explanatory, it has most often been to explain why networks have the structure they do (e.g., proposing preferential-attachment as a

\footnotetext{
${ }^{5}$ For those interested in learning more about the social science approach to network analysis, we recommend a number of review articles and textbooks (57-59).
} 
mechanism for producing scale-free degree distributions). In contrast, the social sciences have focused more on the consequences of network structure for non-network outcomes, such as performance or homogeneity.

Another difference between network research in the physical and social sciences is that the social scientists have been comparatively more concerned with the individual node than with the network as a whole. The main interest for social scientists has been in understanding what happens to the individual node, regardless of whether the node itself represents an individual or a collective (such as a firm). This focus on node-level outcomes is probably driven to at least some extent by the fact that traditional social science theories have largely been individually focused. In order to compete against more established social science theories, network researchers have had to show that network theory can better explain the same kinds of outcomes that have been the traditional focus of the social sciences.

A characteristic of network research in the social sciences is that it tends to preserve distinctions between different kinds of ties because it is thought that the type of tie affects how network structure influences outcomes. In contrast, the physical sciences have tended to treat different kinds of ties as alternative options (varying in quality) for measuring "the" social network. Some physicists argue that direct observation of who interacts with whom would be preferable to asking respondents about their social contacts, on the grounds that survey data is prone to error. Social scientists agree that survey data contains error, but do not regard an error-free measurement of who interacts whom to be a substitute for, say, who trusts whom, as these are qualitatively different ties that can have different outcomes. In addition, social scientists would note that even when objective measures are available, it is often more useful for predicting behavior to measure a person's perception of their world rather than to measure their actual world.

Across all of these distinctions, it is apparent that the physical and social sciences are most comfortable at different points along the (related) continua of universalism to particularism, and simplicity to complexity. From a social scientist's point of view, network research in the physical sciences can seem alarmingly simplistic and coarse-grained. And, no doubt, from a physical scientist's point of view, network research in the social sciences must appear oddly mired in the minute and the particular, using tiny datasets and treating every context as different. This is one of many areas where we can each take lessons from the other. 


\section{References}

1. M. Newman, A. Barabasi, D. J. Watts (Eds.), The Structure and Dynamics of Networks (Princeton University Press and Oxford, Princeton, New Jersey, 2006).

2. L.C. Freeman, The Development of Social Network Analysis: A study in the Sociology of Science (Empirical Press, Vancouver, 2004).

3. J. L. Moreno, Who Shall Survive? (Washington, DC: Nervous and Mental Disease Publishing Company, 1934).

4. E. Durkheim, Suicide: A Study in Sociology (Free Press: New York, 1951).

5. R. Luce, A. Perry, Psychometrika, 14, 95 (1949).

6. A. Bavelas, J. Acoustical Soc. America 22 (1950).

7. H. Leavitt,. J. Abnormal and Social Psychol. 46 (1951).

8. M.E. Shaw, Communication networks, In L. Berkowitz (Ed.), Advances in Experimental Social Psychology, 1, 111 (Academic, New York, 1964).

9 . I. de S., Pool, M. Kochen, Social Networks, 1, 1 (1978)

10. S. Milgram, Psychology Today, 2, 60 (1967).

11. C.S. Fischer, To Dwell Among Friends (The University of Chicago Press, Chicago, IL, 1948)

12. C. E. Hollingshead, Elmtown's Youth (John Wiley and Sons, London, 1949).

13. B. Wellman, J. Salaff, D. Dimitrova, L. Garton, M. Gulia, C. Haythornwaite, Annual Review of Sociology, 22, 213 (1996).

14. R. Brown, Structure and Function in Primitive Society (Free Press, Glencoe, IL, 1952).

15. S. F. Nadel, The Theory of Social Structure (Free Press, Glencoe, IL, 1957).

16. H. White, An Anatomy of Kinship: Mathematical Models for Structures of Cumulated Roles (Prentice Hall, Engelwood, NJ, 1963).

17. J. P. Boyd, Journal of Mathematical Psychology, 6, 139 (1969).

18. E. Bott, Family and Social Network (Tavistock Publications, London, 1957).

19. F.P. Lorrain, H.C. White, Journal of Mathematical Sociology, 1, 49 (1971). 
20. R.S. Burt, Corporate Profits and Cooptation (Academic Press, NY, 1983).

21. R.S. Burt, American Journal of Sociology, 92, 1287 (1987).

22. M.S. Granovetter, American Journal of Sociology, 78, 1360 (1973).

23. R.S. Burt, Structural Holes: The Social Structure of Competition (Harvard University Press, Cambridge, MA. 1992).

24. R. Cross, A. Parker, The Hidden Power of Social Networks (Harvard Business School Press, Boston, $M A, 2004)$.

25. J.A. Levy, B.A. Pescosolido, Social Networks and Health (Elsevier, 2002).

26. M. Sageman, Understanding Terror Networks (University of Pennsylvania Press, Philadelphia, 2004).

27. S.P. Borgatti, In R. Breiger, K. Carley, \& P. Pattison, (Eds.),Dynamic Social Network Modeling and Analysis: Workshop Summary and Papers, 241 (National Academy of Sciences Press, 2003).

28. S. P. Borgatti, Social Networks, 27, 55 (2005).

29. M.S. Granovetter, American Journal of Sociology, 91, 481 (1985).

30. B. Uzzi, American Sociological Review, 61, 674 (1996).

31. J.S. Coleman, American Journal of Sociology, 94, S95 (1988).

32. S.P. Borgatti, M.G. Everett, P. Shirey, Social Networks, 12, 337 (1990).

33. L.C. Freeman, Social Networks, 40, 35 (1977).

34. J.F. Padgett, C.K. Ansell, American Journal of Sociology, 98, 1259 (1994).

35. L. Festinger, S. Schacter, K.W. Back, Social Pressures in Informal Groups: A study of Human Factors in Housing (Harper, New York, 1950).

36. P. M. Blau, Inequality and Heterogeneity: A Primitive Theory of Social Structure (Free Press, New York, 1977).

37. M. McPherson, L Smith-Lovin, J.M. Cook, Annual Review of Sociology, 27, 415 (2001)

38. R. S. Burt, Brokerage and Closure (Oxford University Press, New York, 2005).

39. G. F. Davis, H.R. Greve, American Journal of Sociology, 103, 1 (1997).

40. T. W. Valente, Social Networks, 18, 69 (1996). 
41. R. S. Burt, American Journal of Sociology, 110, 349 (2004).

42. W. Powell, K. Koput, and L. Smith-Doerr, Administrative Science Quarterly, 41, 116 (1996).

43. A.V. Shipilov, S.X. Li, Administrative Science Quarterly, 53, 73 (2008).

44. D. J. Brass, Administrative Science Quarterly, 29, 519 (1984).

45. G.F. Davis, Administrative Science Quarterly, 36,583 (1991).

46. N. Lin, Annual Review of Sociology, 25,467 (1991).

47. T. Yamagishi, M.R. Gilmore, K.S. Cook, American Journal of Sociology, 93, 833 (1988).

48. B. Markovsky, D. Willer, T. Patton, American Sociological Review, 53, 220 (1988).

49. E. Bienstock, P. Bonacich, Social Networks, 14, 231 (1992).

50. L.C. Freeman, Journal of Social Structure, 9 (2) (2008).

51. M. Emirbayer, J. Goodwin, American Journal of Sociology, 99, 1411 (1994).

52. A. Mehra, M. Kilduff, D.J. Brass, Administrative Science Quarterly, 35, 121 (2001).

53. T.A.B. Snijders, Journal of Social Structure, 3, 1 (2002).

54. D. Krackhardt, M. Kilduff, Journal of Personality and Social Psychology, 76, 770 (1999).

55. J. M. Podolny, Status Signals (Princeton University Press, Princeton and Oxford, 2005).

56. A. Giddens, The Constitution of Society (University of California Press, Berkeley and Los Angeles, 1984).

57. S. Wasserman, K. Faust, Social Network Analysis: Methods and Application, (Cambridge University Press, New York, 1994).

58. D.J. Brass, J. Galaskiewicz, H.R. Greve, W. Tsai, Academy of Management Journal , 47, 795 (2004).

59. Wellman, S.D. Berkowitz (eds.), Social Structures: A Network Approach (Cambridge University Press, Cambridge, 1988). 